\title{
Abordagem corporal em terapia sexual
}

Amparo Caridade*

\section{DIMENSÃO SISTÊMICA DA DISFUNÇÃO SEXUAL}

Algo de perigoso acontece quando elegemos e privilegiamos uma esfera da vida, mesmo que seja para estudá-la, para destacá-la no existir. Pinçamos uma parte do grande conjunto, e corremos o risco de deixá-la sem referência ao todo. Imagino as consequiências que isso pode trazer às formas de ver, sentir e pensar as diversas dimensões do viver. Que aspectos da totalidade ficarão imolados nesse olhar micro lançado sobre a questão? Particularizando, interrogo-me se, o superdestaque concedido hoje em dia à sexualidade de forma descontextualizada, não a coloca ansiosamente em foco, a ponto de adoentalizá-la, ao invés de libertá-la? Baudrillard pensa que a sexualidade continua insegura por trás da libertação de seu discurso, e acha até que sua proliferação está próxima do total desperdício. (1)

Parto dessa inquietação para considerar a importância de que a sexualidade seja pensada, inserida no viver em totalidade, isto é, que ela seja situada como um aspecto entre outros do existir humano. Magnificá-la para além de sua dimensão, fazer dela o todo, condição única de felicidade,

* Psicóloga. 
é irreal, pode gerar efeito contrário. Transformá-la num monstro que nos possui, vai torná-la mais sufocante que libertadora. Fazer de sua vivência em moldes pré-estabelecidos, condição de normalidade, pode tirar-the a espontaneidade a empalidecer o bem que ela representa na vida. Por isso a deseleição do sexo-rei, parece-me mais libertadora. Assim o indivíduo poderá sentir-se bem ao gostar de sexo, como gosta de arte, de política, de tocar um instrumento, ser um bom gourmant ou escrever poesias. Não terá de ser atleta sexual para se conformar a padrões estereotipados e consumistas que são impostos.

Uma dimensão humana perpassa as disfunções sexuais, e podemos entendê-la a partir do fato evidente de que somos um todo e funcionamos na inteireza disso que somos. Cresce esse reconhecimento entre os estudiosos e atualmente sopram fortes os ventos do Holismo fazendo ver que a pessoa age em totalidade, entrelaçando-se e interagindo com os outros e com o universo.

Um olhar macro sobre o homem, a vida, o cosmo, procede de revoluções feitas pela física, resultando em interpretações da física sub-atômica, e evidenciando que a natureza deve ser entendida como uma rede dinâmica de eventos interrelacionados, onde nenhuma parte é mais fundamental que qualquer outra. (2) Uma imprevisibilidade no comportamento dos fótons "eventos suaves", que provocam perturbações mínimas, foi evidenciado pela física quântica, e quebrou as rígidas certezas da física clássica, possibilitando o surgimento de novos paradigmas para o estudo da vida a do ser humano. Essas idéias têm uma conseqüência multidisciplinar, sugerem uma interconceptualidade extremamente necessária ao entendimento do que se passa na pessoa. $\mathrm{O}$ todo tem uma dimensão integradora, porque é na organização das partes que se dá a harmonia, que se caracteriza a ordem uma ordem que procede do entrelaçamento das partes. Isso implica que uma parte tem a ver com o todo, e também que só pode ser compreendida nessa relação de totalidade. Compreender uma disfunção sexual, supõe inserí-la no conjunto da existência da pessoa. Não podemos tratá-la, reduzindo-a a uma partícula. Não podemos pensar a disfunção sexual como algo que está errado apenas com os órgãos sexuais. A saúde requer um estado de equilíbrio entre forças ambientais, modos de vida e os vários componentes da natureza humana, já pensava Hipócrates. (3)

O conceito de estresse é bem compatível com a visão sistêmica da vida mas só pode ser bem apreendido quando uma sutil interação mente e corpo é percebida. Estresse pode ser compreendido como um desequilíbrio do organismo em resposta a influências ambientais. Ele ocorre, quando uma ou diversas variáveis do organismo são forçadas até seu limite extremo, o que induz a um aumento de rigidez em todo o sistema. Prolongado, resulta na incapacidade para integradas respostas do corpo a nossos hábitos culturais e regras sociais de comportamento. Por isso ele é fonte geradora de dificul- 
dades sexuais. Estas surgem como gritos do organismo exaurido, seja em sua força física, seu emocional ou dimensão existencial.

A disfunção sexual procede muitas vezes do caminho que vai sendo traçado pelo indivíduo em sua história em sua estruturação da pessoa que é. Nessa trajetória quase sempre ele sacrifica aspectos de si mesmo, emoções, valores, atitudes, em atendimento a exigências educacionais, culturais, e outras, que impedem a inteireza que aqui postulo. Outras vezes a disfunção sexual pode funcionar como sisal como busca de algo mais realizador e mais bonito. Nem tudo deve pois ser patologízado, mas compreendido em sua essência.

Encontro na teoria da metamotização de Maslow (4) uma estreita relação com as questões da sexualidade que aqui abordo. Elo defende a tese de que, quando a pessoa madura tem suas necessidades básicas satisfeitas, passa a ser motivada de modo mais elevado, o que ele chama de metamotivação. Há uma variedade de metamotivos como, impulsos para a verdade, a estética, a auto-realização, que são encontrados em pessoas relativamente saudáveis. Ele acha que a plena definição da pessoa deve incluir valores intrínsecos, não como algo abstrato mas como pane da natureza humana. Essex valores intrínsecos são instintóides diz ele, no sentido de que são necessários para evitar a enfermidade e para atingir a mais plena humanidade. Em consequiência disso, as enfermidades resultantes da privação desses valores intrínsecos - metanecidades - são chamadas de metapatologias. Maslow reconhece uma hierarquia de necessidades básicas que prevalece sobre as metanessidades, mas também refere-se a indivíduos cujo talento especial ou sensibilidade.peculiar, tornam a verdade, a beleza ou a bondade mais importantes e mais urgentes do que alguma necessidade básica. As necessidades básicas são chamadas de necessidades de deficiência, enquanto as metanecessidades são chamadas de motivações de crescimento.

Entendo que as disfunções sexuais podem ser vistas como metapatologias, no sentido de que elas expressam uma desarmonia que atinge o todo da pessoa, e não apenas o funcionamento da genitália. Quase sempre elas procedem dessa totalidade humana prejudicada, porque a sexualidade reúne tanto as dimensões de necessidades básicas como de motivações de crescimento. A grandeza do sexo está nessa vivência em meio aos projetos de felicidade humana, em parceria amorosa, a não apenas com fins procriativos ou numa busca mecânica de um prazer simplista. $O$ homem não se reduz as suas necessidades, e no terreno da sexualidade ele supera a ordem estabelecida pelo orgânico. Ele inventa, cria a cada instante seu modo de ser prazeroso, seu gosto a expressão sexual.

Atravessamos um momento social muito pouco metamotivado. Estamos submetidos à cultura da velocidade, do efêmero, do consumo. Tem-se tanta pressa que o jornal do dia seguinte é vendido na véspera, a 
notícia não pode aguardar o amanhecer. Somos uma cultura onde não há tempo nem energia para as pessoas sentirem-se, e usufruírem de sua potencialidade prazerosa. Em meio à desconfiança, à violência, ao salve-se quem puder, falta chão, e disponibilidade para o desarmamento, a entrega e o abandon o ti ecessário à experiência prazerosa. É nesse contexto que as pessoas exigem-se cada vez mais performance, e um desempenho sexual tecnicizado, capaz de assegurar um funcionamento padrão as nossas máquinas desejantes. $O$ prazer se dá mal com esse modelo. Cresce na minha observação clínica, a queixa de diminuição do desejo, e o desencanto com o prazer obtido, esmagadoramente menor que as expectativas mantidas. As pessoas parecem desconhecer que podem buscar um mais além de si, e perdem-se na circularidade de uma mesmice empobrecedora da experiência sexual, numa mera busca de orgarmos sem nenhum gozo mais além. Vivemos na época da liberação, tempo a impressão da expansão, embora na verdade vivamos em contração. E Gaiarsa diz que toda expansão é prazenteira e toda contração é angustiosa. (5)

\section{O QUE TRATAMOS}

Toda essa forma de ver e pensar o disfuncional humano, descentra o poder curativo das mãos do profissional e deve tornar o indivíduo co-responsável por suae saúde, seu bem ester, sua felicidade. Em nossa cultura instalou-se a idéia do profissional como a de um mago onipotente, totalmente responsabilizado, sem que o cliente nada assume de seu processo de cura. Ele chega para ser objeto de intervenção, vem disponível para submeter-se, não para ser sujeito de qualquer processo. É que não desenvolvemos nenhum respeito pelo processo de auto-cura. "Dar remédios é um símbolo muito poderoso em nossa cultura", diz Capra. Há um comércio de ilusões nessa busca e oferta de certeza de soluções para coisas que nos afligem. Muitas vezes as causas não são atingidas porque isso requer maior envolvimento do sujeito. contudo, somente quando elas são atingidau, o indivíduo começa a responsabilizar-se por sua cura. Muitos clientes não alcançam resultado com a Terapia Sexual, por nã o se tornarem co-responsáveis pelo processo, temendo que isso lhes exija investimentos pessoais por vezes custosos emocionalmente. Nessa culture da velocidade, ele tem pressa, ele quer é livrar-se do sintoma, não pensa na cura como um processo, prefere uma interferência, uma ação mágica, técnica, eficiente, mesmo que sobre o sintoma apenas. Precisamos proporcionar-lhe uma visão sistêmica que encare a questão da saúde em termos de um processo que inclui a resposta criativa do organismo aos desafios ambientais (6). A saúde é um fenômeno multidimensional. 
Tratamos ainda as pessoas com técnicas marcadas pelo dualismo cartesiano. Médicos olham o corpo supostamente avariado, buscando e criando intervenções alternativas para cada caso. Mas uma intervenção restrita, localizada, cura da parte, magia da mecânica. Psicólogos dedilham a história do indivíduo em busca de dores residuais, emoções estressantes, oxalá geradoras do mal estar vivido pelo indivíduo, e quem sabe, ele tome consciência do ser de direitos que é, podendo viver o prazer sem culpa. Educadores em geral, anunciam e denunciam concertos, pré-concertos e formas de lidar com a pessoa em desenvolvimento, para que o amanhã possa nos brindar com sujeitos mais realizados sexualmente. Comunicólogos estampam e denunciam o que, por trás dos bastidores da mídia, se faz à sexualidade humana. Tudo perfeito, se não víssemos nisso um sintoma de nossa fragmentação, de nossa correria onde tudo converge "natural" e perigosamente para ações individualizadas, onde cada um faz a sua parte. E quem reunira o esfacelamento resultante? Mais que encastelar-se em seu saber especializado, cada profíssional é convocado a somar e a possibilitar uma síntese que seja geradora da maior segurança para o cliente. A quebra de onipotências e a partilha interconceptual são aqui muito bem-vindas.

Nossa prática profissional também sofre os impactos da cultura veloz e efêmera, e queremos poder oferecer um tratamento rápido a eficiente, condizente cum a pressa dos tempos atuais. Isso é reciprocamente enganoso a cliente e terapeuta. Adoecer e sarar são ambos partes integrantes da autoorganização de um organismo, diz F. Capra (7), o que supõe ação demorada. A cura é processual, não importa por que prisma teórico a enfoquemos. A retenção das emoções, por exemplo, é fator crucial no desenvolvimento das doenças e das disfunções. Ora a cura exige a libertação dessas emoções aprisionadas e isso requer tempo e disponibilidade interna do sujeito. Joyce Mc Dougall lembra que o afeto é suprimido do psiquismo é liberado nos sintomas neuróticos (8). É muito forte hoje em nossa cultura esse traço, essa supressão do afeto, uma armadura que endurece, a essa emoção expulsa do psiquismo exige recuperação, uma técnica poderá ser útil para facilitar o acesso a tal emoção, mas nada se resolve se ela não for contactada, compreendida, trabalhada, desmistificada, para que se reduza o poder inibidor que exerce.

Talvez tenhamos que sarar da pressa e da superficiabilidade em que vivemos para facilitar o bem estar do cliente que nos procura. Querer obter a cura a qualquer preço, diz Groddeck (9), é forçar o doente a apresentar sintomas mais graves ainda, porque o que age no sintoma não é tanto o fator exógeno, mas o símbolo, e ele está ancorado no imaginário de cada um. Leva tempo para ser decifrado, compreendido e assumido. Desvendado o processo de recalcamento no sujeito, Freud o revela em 3 tempos: primeiro, o recalque primordial; segundo, o recalque propriamente dito; e terceiro, o retorno do recalcado.(10) Ora o retorno do recalcado é o motivo próprio dos sintomas, e terá que ser elucidado para ser recusado. 
Penso que uma disfunção sexual pode ter também o sentido desse retorno do recalcado, a pode estar ancorada em angústias que se anunciam agora em forma de sintoma, de impedimento de desempenho a satisfação sexual. Essas angústias que foram se aninhando na história do sujeito, podem constituir o terreno sobre o qual se desenvolvem as disfunções sexuais. Diante disso, teremos de tratar a pessoa disfuncional não a disfunção. Vale lembrar a propósito o que diz Gabriel G. Marquez: "Não há remédio que cure o que a felicidade não cura". (I 1) Daí a necessidade de que o cliente encontre condições de resgate ea felicidade perdida.

\section{TÉCNICA AJUdA, MAS NÃO CURA}

A técnica é um recurso que utilizamos para facilitar o desembaraço do corpo, o desvencilhamento de si mesmo. Mas esse desembaraço acontece quando procede de um movimento interno do sujeito. Receio que em nosso exercício profissional, haja um encantamento pelo uso da técnica, resultando em ritualização mecânica, ou na idéia simplista de mágicas soluções para as disfunções sexuais. Uma técnica jamais deve conduzir o indivíduo para longe de si. Ela deve ser instrumento facilitador da intimidade do indivíduo consigo, cum sua interioridade e não uma ginástica do distanciamento como diz Neidhoefer (12), uma técnica jamais deve servir de escudo às incertezas e inseguranças do terapeuta. Nenhuma magia é oferecida pelo mosaico de técnicas e terapias corporais que dispomos. Aplicar uma técnica, supõe que o corpo do terapeuta a suporte a dela se beneficie, do contrário como veicular uma crença em seu valor? O corpo do terapeuta funciona como um espelho, e não pode refletir o que nele não existe. Harmonia, suavidade, soltura, sensibilidade não se improvisam. Devem ser buscadas no cotidiano. Isto é necessário porque a sensibilidade para perceber o cliente depende do quanto sentimos e observamos nosso próprio corpo.

A ajuda oferecida pela técnica deve remeter o cliente a fazer contato com as sensações que lhe fluem no aqui e agora, porque quando esse contato se dá, o sentir torna-se mais intenso, a vida mais viva, e a identidade mais presente na consciência, uma ritualização mecânica destituída desse sentido pode ser eficaz apenas temporariamente ou até mesmo inócua, porque não possibilita a compreensão dinâmica da pessoa e do que subjaz à dificuldade existente. Por isso é necessário entender como atuam as técnicas, o que cada um pode mobilizar no psiquismo do indivíduo. $\mathrm{Na}$ verdade ela só beneficiará o trabalho terapêutico se houver por parte do cliente uma prontidão para assimilá-la e dela tirar proveito. Caso contrário será iatrogênica, poderá reforçar defessas maiores. Os focos sensórios, por exemplo, se utilizados quando há conflitos, desafeto, rejeição, intolerância, mágoas e outros sofrimentos relacionais, podem apenas cristalizar e inten- 
sificar recusas, ou promover falsas resoluções das dificuldades. não adianta por exemplo, mandar soltar a pelve através de um técnica se algo interiormente algema essa parte. De nada adianta insistir na afirmativa de que esse balanço pélvico causa prazer, se ronda para a pessoa o fantasma arcaico de que o prazer é feio, é pecado, ou se lhe pesa na memória alguma experiência traumática dolorosa, ainda não trabalhada.

Aprecio técnicas mais globalizantes, porque além de desenvolverem uma sensibilidade de conjunto, elas perdem qualquer caráter de mecânica. Assim, sugerir um resgate da sensoriabilidade global do corpo é altamente benéfico à sexualidade como um todo, e descentra o indivíduo da disfunção específica que lhe era tanta ansiedade. O exercício dos diversos órgãos dos sentidos fica muito enriquecedor, é resgatador da sensibilidade a leva o indivíduo a um contato maior consigo mesmo. Eles são a porta da sensação, a via do prazer. As atividades da vida diária podem servir ao exercício da sensorialidade. Podemos sugerir um despertar cutâneo geral por exemplo no banho, através das sensações de escorrimento da água no corpo, da temperatura, do barulho do chuveiro, a sensação de uma esponja ou a maciez da espuma na pele, o cheiro do sabonete, etc. É importante que uma sensorialidade possa se dar primeiro na experiência privada do indivíduo e só depois ele está mais apto para partilhá-la com outro em intensidade. $\mathrm{O}$ estado de insegurança procede de nossas dúvidas do que sentimos, aí passamos a valorizar a opinião dos outros. Quando conhecemos e confiamos em nossas sensações elas servem de referenciais aos nossos desempenhos, porque nos põem contato com nosso próprio eixo. $\mathrm{O}$ ato de comer percebendo o gosto de cada coisa, o visual e cheiro do prato, o prazer disso, a sensualidade da fruta, tudo exercita a grande sensibilidade que encaminha uma interação mais prazerosa com o m undo externo. Se não formos onipotentes, poderemos questionar o cliente acerca do que pode ser inventado entre parceiros, que lhes facilite a soltura, o encontro. O que dele proceder como sugestão sofrerá menor resistência.

Outras técnicas endereçam a uma entrega maior. Isso também não é mecânico, está muito presente no modo de ser da pessoa. O indivíduo tenso, prevenido, desconfiado não se entrega. Entrega é tanto a soltura de um feixe de músculos, como a busca de uma sensação mais profunda, a atitude de disponibilidade interna, ou o abandono à contemplação de algo, seja uma paisagem, um poema, ou os olhos do amado. Entrega é deixar-se aprisionar pelo olhar do outro, por seu mistério. No olhar que se cruza, diz A. da Távola, o imo de cada um encontra a instância deslumbrante onde se descobre aceito, querido, perdoado e permitido. (13) Entrega é até seduzir e deixar-se seduzir numa busca ilusória de um objeto-bens, uma espécie de convocação do nada ou do tudo. Sibony fala disso mostrando que o jogo é um gozo, e que a sedução é um jogo que faz mais questão de seu desregramento que de suas regras, de seu prosseguimento mais que de seu tér- 
mino. (14) Com isso ele confirma que o desafio maior é esse do gozo, e não a posse sexual do outro.

Exercícios orientados de relaxação auxiliam em muito a entrega, quando um desejo interno já está mobilizado no indivíduo. Respirar bem, com consciência da pulsação da vida em si, é caminho de contato inclusive com os sentimentos mais fundos. O terapeuta criativo, atuando em nível de atenção flutuante, pode endereçar esses relaxes a situações específicas das disfunções existentes, como por exemplo, sugerir a busca do prazer de abandonar-se no tempo pode ser muito útil a um ejaculador precoce; ou identificar a presença e sensações dos órgãos sexuais, do mesmo modo que percebe e sente o coração bater, o pulmão respirar, a vida inteira pulsar no corpo, ajuda a experimentar sensações mesmo as erógenas, sem ansiedade.

A logoterapia de Viktor Frankl (15) elaborou algumas técnicas para a atuação prática, que servem particularmente ao trabalho com as dificuldades sexuais. Ele discute a ansiedade antecipatória, como o medo provocando o sintoma do qual se tem medo. O sintoma agrava-se criando-se um círculo vicioso que vai se colocar na base de muitas dificuldades sexuais. Por exemplo: quando surge o desejo, o indivíduo começa a sentir medo de não conseguir bom desempenho na relação. Pensa tanto nisso, que se impede de entregar-se à sensação prazerosa. $\mathrm{O}$ círculo agrava-se e o cliente chega a ter medo de ter medo, não consegue ereção por medo de não conseguir. Cristalizado na idéia fixa do desempenho termina por fracassar. Frankl sugere que o cliente procure não conseguir, e que durante uma semana, por exemplo, ele agrave seu sintoma. É a intenção pardoxal, uma técnica que atua na desfeita do círculo vicioso. Proibido de sair de seu sintoma, de sua dor, rompe o círculo, porque "o homem é vocacionado à liberdade". Nele toda espécie de repressão reforça o sentido da liberdade humana, A luta contra o sofrimento gera o próprio sofrimento, a luta contra o medo gera o medo, a luta contra a doença faz crescer a enfermidade. É um processo de auto-hipnose no sentido de reforçar o sintoma. A derreflexão é outra técnica que trabalha mais na resolução dos conflitos sexuais e contra a luta para se conseguir prazer. Isto por si só, é uma forma de não encontrá-lo. A derreflexão tenta deslocar a atenção do cliente preocupado com seu sintoma para outra coisa mais ampla da vida e mais importante, como sugerir que não melhore nos 3 primeiros meses, mas elabore alguns projetos de vida futura. O sintoma é a linguagem de um sofrimento interno do indivíduo. $\mathrm{O}$ que é mais grave está dentro do indivíduo, não no sintoma, quase sempre se privilegie o sintoma sobre o sofrimento real, que o Próprio cliente nem sempre quer ver. "A derreflexão atua rompendo o círculo da hipertensão que agrava a hiper-reflexão em um contínuo processo de busca obsessiva de se conseguir o prazer". A Logoterapia preocupa-se com a superação do vazio existencial, da falta de razão para viver. 
A apelação é também um recurso que conduz ao reavivamento da riqueza sentimental e afetiva da pessoa perturbada. Consiste em valorizar o sentimento do cliente quando ele chora, ri, alegra-se ou fica triste. implica em sublinhar o lado forte da pessoa que se sente enfraquecida. Esse uso depende da criatividade, do bom senso de do contexto da relação terapêutica. Por fim o diálogo socrático é proposto durante todo o processo, e serve ao auto-conhecimento. Possibilita que o ciente entre em contato com seu incosciente, com o sentido de sua vida, seu potencial humano e a direção que quer dar a vida.

A filosofia tântrica postula uma entrega total ao exercícioda sexualidade e mostra que a vontade é causa de toda ansiedade (16). De fato, vemos no contexto das dísfunções sexuais que a hiperintencionalidade, (17) a vontade obstinada de desempenho ótimo da sexualidade é um dos maiores obstáculos ao seu exercício. Alguns passos são sugeridos na busca da plenitude da experiência sexual, que é a proposta básica do Tantra: (18)

1 - "Não se apresse, não anseie pelo final. O começo é mais relaxado e mais caloroso. Permaneça no presente. Goze o encontro de dois corpos, duas almas e mergulhem um no outro. No contato com o sexo oposto cada célula sua é desafiada e excitada." Essa proposta é muito interessante para uma cultura. como a nossa que supervaloriza o desempenho a descuida do contato, da emoção e da profundidade da sensação que conduz ao estado de gozo.

2- "No início de uma união sexual preste atenção no fogo, e evite as brasas do final. Se a ejaculação se dá, a energia se dissipa, não existe mais fogo. Você se alivia da energia sem ganhar nada”. Imagino a importância dessa descoberta para quem só valoriza o quantitativo em detrimento da qualidade, ou para quem não presta atenção ao prazer da parceira, fatos muitos comuns em nossa realidade. Lamentavelmente a cultura rios passa uma compreensão do gozo apenas como orgasmo e não enquanto estado orgástico.

3- "Ao recordar-se da união, vem a transformação. Você pode mergulhar no ato até mesmo sem o parceiro, (através da lembrança do que já viveu) se tiver dentro de si o sentimento quando havia apenas uma energia que os tornou uma unidade", ou seja, se voce registrou no espírito um momento de fusão e perda do eu.

É preciso a experiência do perder-se para encontrar-se na fusão na unidade. É preciso a valorização da memória porque a retrospectiva, a reminiscência do vivido, é também plena de gozo. Bachelard diz isso poeticamente: "Inventa! Não há festa perdida no fundo da memória."(19)

Tudo parece muito genérico, e pode ao mesmo tempo ser muito familiar. É que a sexualidade não é concreta como imaginamos. Pelo contrário, ela é contínua invenção do espírito humano. Até mesmo quando estamos em contato com o corpo do outro, lidamos com uma grande metá- 
fora. R. Barthes fala de um vasculhar o corpo no outro, como se quisesse ver o que tem dentro dele, como se a causa mecânica do meu desejo estivesse no corpo adverso' diz ele, a faz a imagem: "(me pareço corri esses garotos que desmontam um despertador para saber o que é o tempo)"(20). Por mais que aprendamos sobre a sexualidade, suas disfunções e suas curas, teremos de olhar com singularidade a engrenagem de cada indivíduo. Teremos de ajudar o cliente a desmontar seu próprio desejo, para compreender onde se deu o nó que o impede de acontecer.

\section{REFERÊNCIAS BIBLIOGRÁFICAS}

1. BAUDRILlaRD, J. Da sedução. Papirus Campinas. 1992.

2. CAPRA, F. Sabedoria incomum. Cultrix. São Paulo. 1988.

$3 . \quad$ Idem.

4. MASLOW, A. in Além do ego. Cultrix. São Paulo. 1980.

5. GAIARSA, A. Sexo, Reich e etc. Agora. São Paulo. 1985.

6. CAPRA, F. Idem.

$7 . \quad$ Idem.

8. Mc DOUGALL, J. Teatros do eu. Francisco Alves, Rio do Janeiro. 1992.

9. EPIGNAY, M. Croddeck: a doença como linguagem. Papirus. São Paulo. 1983.

10. SAFOUAN, M. O fracasso do princípio do prazer. Papirus. São Paulo. 1988.

11. MARQUEZ, G.G. Do amor e outros demônios. Record. Rio de Janeiro. 1994.

12. NEIDHOEFER, L. Trabalho corporal intuitivo. Summus Ed. São Paulo.

13. TAVOLA, A. Do amor: ensaio de enigma. Nova Fronteira. Rio deJanciro. 1983.

14. SIBONY D. Sedução. O amor inconsciente. Brasilience. São Paulo. 1991.

15. GOMES, J. C. V. Logoterapia. Loyola. São Paulo. 1987.

16. RAJNEESH, B. S. Tantra. Sexo e espiritualidade. Agora. São Paulo. 1977.

17. FRANKL. V. Fundamentos antropológicos da psicoterapia. Zahar. Rio de Janeiro.

18. RAJNEESH, B. S. Idem.

19. BACHELARD, G. A poética do devaneio. Martins Fontes. São Paulo. 1988.

20. BARTHES, R. Fragmentos de um discurso amoroso. Francisco Alves. Rio do Janeiro. 1989. 